\title{
Critical analysis of thoracotomies performed in the emergency room in 10 years
}

\section{Análise crítica das toracotomias realizadas na sala de emergência durante 10 anos}

\author{
Marcelo Beck Guimaräes'; Diego Carrão Winckler'; Nádia Gabriele Rudnick'; Ricardo Breigeiron, TCBC-RS'1
}

\author{
A B S T R A C T
}

\begin{abstract}
Objective: To conduct a critical analysis of thoracotomies performed in the emergency rooms. Methods: We analyzed mortality rates and survival as outcome variables, mechanism of injury, site of injury and anatomic injury as clinical variables, and gender and age as demographic variables of patients undergoing thoracotomy in the emergency room after traumatic injury. Results: Of the 105 patients, 89.5\% were male. The average age was 29.2 years. Penetrating trauma accounted for $81 \%$ of cases. The most common mechanism of trauma was wound by a firearm projectile (gunshot), in $64.7 \%$ of cases. Patients with stab wounds (SW) accounted for $16.2 \%$ of cases. Overall survival was $4.7 \%$. Survival by gunshot was $1.4 \%$, and by SW, $23.5 \%$. The ERT following blunt trauma showed a $100 \%$ mortality. Conclusion: The results obtained in the Emergency Hospital of Porto Alegre POA-HPS are similar to those reported in the world literature.
\end{abstract}

Key words: Thoracotomy. Wounds and Injuries. Thoracic Injuries. Thoracic Surgical Procedures.

\section{INTRODUCTION}

C hest injuries represent a leading cause of death in all age groups, accounting for $25-30 \%$ of all traumatic injuries ${ }^{1}$. Although most penetrating injuries of the chest can be managed conservatively or through less invasive procedures, certain lesions are potentially fatal, mortality reaching $80-90 \%$. Thus, a small group of 10 to $15 \%$ of patients requires immediate thoracotomy as part of initial care ${ }^{2}$. Thoracotomy in the emergency room (ERT) is a heroic procedure that, in selected cases, can be life-saving ${ }^{2}$.

With the expansion of the Mobile Emergency Care Service (SAMU) and the standardization of pre-hospital care, an increasing number of severe trauma patients arrive at the hospital, many in critical condition and impending cardiac arrest. Heaving once belonged to the first peak of the trimodal distribution of trauma deaths, these patients are increasingly being treated in trauma centers. For such patients, ERT may be indicated. As important as the procedure are its correct indication and proper handling ${ }^{3-5}$.

Of the patients who come to the ER with chest trauma, the vast majority, about $90 \%$, has a resolution by nonoperative management or minimum procedures such as thoracostomy for drainage of pneumothorax or hemothorax. Among the remaining are included cases of small number, but of great significance, which require thoracotomy for resuscitation as the only measure able to secure survival.

The resuscitation thoracotomy, or thoracotomy in the emergency room (ERT), refers to thoracotomy included in the initial resuscitation of the agonizing traumatized, whose goal is to prevent the fatal outcome. This operation must be done in the in extremis patient, one that is almost dead, however displaying vital signs or detectable signs of life, because otherwise the resuscitation efforts would be in vain, resulting in unnecessary expense to the system ${ }^{4-6}$.

The indications remain controversial and some directions are suggested by guidelines for the routine trauma care and are accepted: in patients with signs of life, ERT is always indicated when the trauma is penetrating; in patients with no pulse and apnea, other signs of life should be sought, such as pupillary reflex or cardiac activity; if absent, resuscitation maneuvers are contraindicated; in patients with blunt trauma, ERT is justified only if there are signs of life at the beginning of the procedure. It is not indicated if there is no response after five minutes of resuscitation maneuvers in blunt trauma or after 15 minutes in penetrating trauma 5,7 ; in patients with abdominal vascular trauma with major bleeding that progress to cardiopulmonary arrest (CPA). The main determinants of survival in ERT are the mechanism of injury, the location of the lesion and the presence or absence of vital signs ${ }^{2}$.

1. Porto Alegre Emergency Room in - HPS-POA, Porto Alegre, State of Rio Grande do Sul, Brasil. 
The aim of this study was to conduct a critical analysis of the ERT cases at the City of Porto Alegre Emergency Room (POA-HPS).

\section{METHODS}

We studied patients undergoing thoracotomy in the POA-HPS emergency room after traumatic injury, from February 2004 to December 2013.

The sample of patients was selected and studied through prospective analysis of patients' records, and filling out the registration form in that institution. The selection criteria for the indication of ERT were: 1) pre-hospital cardiopulmonary arrest assisted with less than 15 minutes duration, resulting from penetrating chest trauma; 2) assisted pre-hospital cardiac arrest with less than five minutes duration due to non-thoracic penetrating trauma or blunt trauma; 3$)$ severe $(<60$ $\mathrm{mmHg}$ ) and persistent hypotension due to cardiac tamponade and intrathoracic, intra-abdominal, extremities or cervical hemorrhage, or air embolism; and 4) Intra-hospital CPA by blunt trauma with suspected massive hemorrhage or by penetrating trauma. Besides those who did not meet the above criteria, we excluded from the study those whose thoracotomies were performed out of the emergency room and patients with associated traumatic brain injury (TBI).

The sample was subjected to analysis by study of mortality rates and survival as outcome variables; mechanism of injury, site of injury and anatomic injury as clinical variables; and gender and age as demographic variables.

There was no need of the patients' informed consent, since this work is based on data analysis, there being no possibility of change in patients' treatments, and there is no disclosure of names.

\section{RESULTS}

There were 136 thoracotomies performed in the emergency room of the HPS-POA. Of these, 31 patients were excluded due to lack of correct description of injuries, trauma mechanism, procedures performed, association with TBI or without certain prehospital CPA time, in addition to the cases that did not meet the criteria selection of work protocol.

The analysis of the remaining 105 patients showed that $89.5 \%$ (94) were male. The average age was 29.2 years, with extremes of four and 65 . Penetrating trauma accounted for most of the ERT indications, with $81 \%$ of cases, $19 \%$ being for blunt trauma. The most common trauma mechanism was gunshot wound, with $64.76 \%$ of the cases and the stab wounds were found in $16.2 \%$. The heart was the most frequently injured organ in trauma from firearms and stabbing. The spleen was the most affected organ in blunt trauma (Table 1).

Regarding outcome variables, overall survival was $4.76 \%$. When analyzing the specific survival for trauma mechanism and patients undergoing ERT, we observed survival of $1.47 \%$ in victims of gunshot wounds, while the victims of stab wounds displayed a survival rate of $23.52 \%$. Patients submitted to ERT due to blunt had mortality of $100 \%$.

\section{DISCUSSION}

A review of the literature on ERT demonstrates variations in terminology, sample size and reliability of the available studies. Some trauma centers are based on protocols to decide for such intervention, while others are mainly based on the judgment and experience of the attending surgeons. This means that, even after more than 50 years of its popularization, ERT is not well established in the medical literature, becoming the subject of numerous controversies. This great heterogeneity of indications and applications of the procedure is evident by the wide variability in survival rates reported in the medical literature after ERT, ranging from zero to $38 \%{ }^{8-11}$.

It should be noted that an immediate thoracotomy can be performed in the operating room, called emergency thoracotomy (ET), or in the emergency room, (ERT). The latter, popularly called resuscitation thoracotomy was the procedure assessed in this work. Survival rates after an immediate thoracotomy consequent to penetrating chest trauma are commonly reported between 9 and $12 \%{ }^{8-11}$, although there are reports of 38\% survival ${ }^{11}$. Many efforts are being made to identify which patients would benefit from thoracotomy in the emergency room.

The American College of Surgeons reviewed all English language publications in the "National Library of Medicine" and "Medline" between the years 1966 and 1999, searching for the terms: "penetrating heart injuries", "penetrating cardiac injuries", "cardiac injuries",

Table 1 - Relationship between organs affected by the trauma mechanism.

\begin{tabular}{lccc}
\hline Organ Affected & $\begin{array}{c}\text { Gunshot } \\
\text { Wounds }\end{array}$ & $\begin{array}{c}\text { Stab } \\
\text { Wounds }\end{array}$ & Blunt \\
\hline Lung & 6 & 2 & 3 \\
Heart & 15 & 8 & 1 \\
Thoracic great vessels & 8 & 2 & 2 \\
Great vessels abdominal & 6 & 1 & 0 \\
Spleen & 3 & 0 & 4 \\
Liver & 3 & 1 & 2 \\
Unidentified & 29 & 4 & 8 \\
Total & 70 & 18 & 20 \\
\hline
\end{tabular}


"emergency department thoracotomy", "resuscitative thoracotomy", and "emergency department thoracotomy in pediatric patients". After careful analysis and classification of level of evidence, 42 studies that dealt with ERT and mortality outcome were selected with level II evidence, with a survival rate of $7.8 \%$. However, when the groups were stratified by type of injury (blunt or penetrating), survival drops to $1.6 \%$ for the blunt injury group and reaches $11.1 \%$ in cases of penetrating wounds ${ }^{4}$, results very close to those obtained in this series.

In a recent European cohort, the survival rate was around $25 \%$ for thoracotomies in the emergency room. These results are even more encouraging when rates of neurological sequelae approach zero ${ }^{12}$. In another European study, the Glasgow series, the median survival of emergency thoracotomies was $32 \%$. However, when the ERT group isolated, the rate dropped to $6 \%{ }^{11}$.

As noted, the literature shows that the best results in terms of survival are related to penetrating trauma, especially when there is an isolated cardiac lesion ${ }^{13}$. Among the penetrating trauma, thoracic stab wounds showed superior survival after ERT relative to other mechanisms of trauma. The blunt trauma, on its turn, showed the worst results of the same outcome after that procedure 2,3,13-15.

Other publications deserve consideration by jointly analyzing several works in the literature and allowing comparisons with the results of HPS-POA. Branney et al. conducted a retrospective study analyzing a sample of 868 patients undergoing ERT for a period of 23 years and found an overall survival rate of $5 \%{ }^{14}$. Of the patients with blunt trauma, 2\% survived the procedure, while patients with penetrating trauma had a survival rate of $7 \%$. A specific analysis of penetrating trauma showed greater survival in patients with stab wounds (14\%) than with gunshot wounds (4\%). Rhee et al. revised 4,620 cases of ERT in a 25-year literature. The overall survival rate found was $7.4 \%$, and the survival of penetrating trauma was $8.8 \%$, the blunt trauma one being only $1.4 \%{ }^{13}$. Also in this review, patients with injuries by stab wounds showed better prognosis, with a rate of $16.8 \%$ survival compared with those wounded by gunshot wounds, which reached only 4.3\%. Another analysis conducted by this study concerns the relationship of survival with the affected organs, showing better survival of ERT in victims of chest injury $(10.7 \%)$ than abdominal injury $(4.5 \%)$. The survival rate was higher for cases of cardiac injury, reaching $19.4 \%$. Fraga et al. conducted a retrospective study of 126 patients undergoing ERT in a period between January 1995 and December 2004 and found a mortality rate of $98 \%$ and an overall survival of $1.6 \%$, represented by only two cases, one by stab wound and another by blunt trauma. The three leading causes of death reported were bleeding, coagulation disorders and brain damage ${ }^{3}$.

Finally, an analysis of the results obtained at the Department of Trauma Surgery in HPS-POA shows an overall survival rate of $4.7 \%$. The specific rate of survival for trauma mechanism was $23.5 \%$ for stab wounds and $1.4 \%$ for gunshot wounds. However, patients who suffered blunt trauma showed $100 \%$ mortality.

The analysis and comparison of the presented studies allow some important considerations. As can be seen, the outcomes found in this study are similar to those found in studies that made use of larger samples. Thus, it is correct to infer that the results are in agreement with the literature data. Exception is made to the survival rate for stab wounds, which proved to be higher. Still, the proportion of the results demonstrates that the better prognosis presented by patients undergoing ERT due to penetrating trauma, especially stab wounds, reported elsewhere, was reproduced in HPS-POA during the ten years of study. Moreover, the worst prognosis of victims of blunt trauma, presented by the world literature through a survival rate ranging from 0 to $2.5 \%{ }^{2,16}$, was also demonstrated in this study. The worst prognosis presented by victims of blunt trauma is probably related to the high values of Injury Severity Score (ISS), since it deals with severe injuries occurring in more than one system. Thus, these patients present with several potential bleeding sites ${ }^{16}$. The better outcomes achieved in victims of stab wounds may be associated with the low-energy trauma mechanism and, consequently, with its low potential for injury as compared with gunshot wounds.

The ERT is a heroic procedure and therefore an exception, which can save the patient's life when properly indicated. A review of previous studies indicates that the best results are obtained in patients suffering from isolated penetrating trauma to the chest arriving with signs of life in the emergency. When there is cardiac tamponade, the prognosis is even better ${ }^{17}$. Blunt and extrathoracic traumas display worse results with ERT, and therefore have very restricted indications ${ }^{6}$.

The analysis in our study shows that the results obtained with the thoracotomy performed in the emergency room of the Emergency Room of Porto Alegre are similar to those reported in the world literature. 


\section{R E S U M O}

Objetivo: realizar uma análise crítica das toracotomias realizadas nas salas de emergência. Métodos: foram analisadas as taxas de mortalidade e sobrevida como variáveis de desfecho, mecanismo de trauma, local da lesão e lesões anatômicas como variáveis clínicas, sexo e idade como variáveis demográficas dos pacientes submetidos à toracotomia, na sala de emergência, após lesão traumática. Resultados: análise de 105 pacientes mostrou que 89,5\% eram do sexo masculino. A média de idade foi 29,2 anos. 0 trauma penetrante respondeu por $81 \%$ dos casos. O mecanismo de trauma mais frequente foi o ferimento por projétil de arma de fogo (FPAF) com $64,7 \%$ dos casos. Os pacientes com ferimento por arma branca (FAB) responderam por $16,2 \%$ dos casos. A sobrevida global foi 4,7\%. A sobrevida por FPAF foi 1,4\% e por FAB, de 23,5\%. A TSE por trauma contuso obteve mortalidade de 100\%. Conclusão: os resultados obtidos no Hospital de Pronto Socorro de Porto Alegre HPS-POA são semelhantes aos relatados na literatura mundial.

Descritores: Toracotomia. Ferimentos e Lesões. Traumatismos Torácicos. Procedimentos Cirúrgicos Torácicos.

\section{REFERENCES}

1. MacKenzie EJ. Epidemiology of injuries: current trends and future challenges. Epidemiol Rev. 2000;22(1):112-9.

2. Coimbra R. Toracotomia na sala de emergência. In: Souza HP, Breigeiron R, Gabiatti G. Cirurgia do Trauma: Condutas Diagnósticas e Terapêuticas. Rio de Janeiro: Atheneu; 2003. p.119-26.

3. Fraga GP, Genghini EB, Mantovani M, Cortinas LGO, Prandi Filho W. Toracotomia de reanimação: racionalização do uso do procedimento. Rev Col Bras Cir. 2006;33(6):354-60.

4. Working Group, Ad Hoc Subcommittee on Outcomes, American College of Surgeons. Committee on Trauma. Practice management guidelines for emergency department thoracotomy. Working Group, Ad Hoc Subcommittee on Outcomes, American College of Surgeons-Committee on Trauma. J Am Coll Surg. 2001;193(3):3039.

5. Colégio Americano de Cirurgiões, Advanced Trauma Life Suport ( $($ ATLS () ), Manual do Aluno. 9a ed; 2014.

6. Ferrada R, Garcia A. Torso: penetrating trauma. Adv Trauma Crit Care. 1993;8:85-116

7. Stockinger ZT, McSwain NE Jr. Additional evidence in support of withholding or terminating cardiopulmonar resuscitation for trauma patients in the field. J Am Coll Surg. 2004;198(2):227-31.

8. Søreide K, Petrone P, Asensio JA. Emergency thoracotomy in trauma: rationale, risks and realities. Scand J Surg. 2007;96(1):4-10.

9. Sheppard FR, Cothren CC, Moore EE, Orfanakis A, Ciesla DJ, Johnson JL, et al. Emergency department resuscitative thoracotomy for nontorso injuries. Surgery. 2006;139(4):574-6.

10. Hunt PA, Greaves I, Owens WA. Emergency thoracotomy in thoracic trauma-a review. Injury. 2006;37(1):1-19.

11. Bleetman A, Kasem H, Crawford R. Review of emergency thoracotomy for chest injuries in patients attending a UK Accident and Emergency department. Injury. 1996;27(2):129-32.
12. Van Waes OJ, Van Riet PA, Van Lieshout EM, Hartog DD. Immediate thoracotomy for penetrating injuries: ten years' experience at a Dutch level I trauma center. Eur J Trauma Emerg Surg. 2012;38(5):543-51.

13. Rhee PM, Acosta J, Bridgeman A, Wang D, Jordan M, Rich N. Survival after emergency department thoracotomy: review of published data from the past 25 years. J Am Coll Surg. 2000;190(3):288-98.

14. Branney SW, Moore EE, Feldhaus KM, Wolfe RE. Critical analysis of two decades of experience with postinjury emergency department thoracotomy in a regional trauma center. J Trauma. 1998;45(1):87-94; discussion 94-5.

15. Brohi K. Emergency department thoracotomy: indications and technique of resuscitative thoracotomy. Trauma.org [periódicos na internet]. 2006 [acesso em: 16 Jul 2014]. Disponível em http:// www.trauma.org/index.php/main/article/361

16. Karmy-Jones R, Nathens A, Jurkovich GJ, Shatz DV, Brundage $S$, Wall MJ Jr, et al. Urgent and emergent thoracotomy for penetrating chest trauma. J Trauma. 2004;56(3):664-8; discussion 668-9.

17. Tyburski JG, Astra L, Wilson RF, Dente C, Steffes C. Factors affecting prognosis with penetrating wounds of the heart. J Trauma. 2000;48(4):587-90; discussion 590-1.

Received on 30/01/2014

Accepted for publication 02/03/2014

Conflict of interest: none.

Source of funding: none.

Mailing address:

Marcelo Guimaraes Beck

E-mail: marcelo.bg@terra.com.br 